\title{
Preliminary and ongoing French multicenter prospective naturalistic study of adverse events of antipsychotic treatment in naive children and adolescents
}

Marie-Line Menard $^{1 *}$, Susanne Thümmler ${ }^{1}$, Philippe Auby ${ }^{2}$ and Florence Askenazy ${ }^{1}$

\begin{abstract}
Background: The prescription of antipsychotics (AP), and especially second generation AP, is increasing worldwide in the pediatric population. Most prescriptions are off-label and despite the identification of frequent and potentially severe adverse events (AE), there are only a few guidelines for the safety management. France is one of the countries with no official safety guidelines.
\end{abstract}

Methods: Psychotropic drug-naive adolescents (13-18 years), hospitalized for an acute psychotic episode and treated with a second-generation antipsychotic were consecutively included in a prospective cohort study. Patients were assessed for their AE at baseline, 2, 6 and 12 weeks after the introduction of drug.

Results: The majority of patients was treated with risperidone $(n=13), 2$ with aripiprazole. The principal findings are: (1) A high incidence of neuromuscular AE: 8/15 muscle weakness, 8/15 extrapyramidal syndrome, 6/15 akathisia, 3/15 oro-facial acute dystonia; (2) Severe catatonia symptoms in 2 patients despite a low to moderate treatment dose, requiring transfer in intensive care unit for one; (3) Weight gain and significant increase of the BMI for all 13 patients who had a 12 weeks follow-up.

Conclusion: All adolescents experienced AE, with significant weight gain being observed in all patients who completed the 12-week follow-up. The fact that our patient population was first episode drug naïve may partially explain this observation. Despite the limitation due to the small sample size of this prospective short-term study, such findings are important to report and warrant further research.

Clinical and research implication: Because of the lack of naturalistic follow up studies of antipsychotic treatments in AP-naive children and adolescents and the absence of safety guidelines for the pediatric population in France, we decided to continue our research at a national level. We therefore started a prospective, naturalistic and multicenter study funded by the French National Agency for Medicines and Health Products Safety (ANSM). Study purpose is to evaluate the incidence of adverse events related to antipsychotic drugs in AP-naive children and adolescents. In addition, we aim to provide further evidence for the necessity of national safety guidelines for AP prescription in the pediatric population.

Keywords: Adverse drug events, Antipsychotics, Therapeutic drug monitoring, Drug-naïve population, Child psychiatry, Pediatrics

\footnotetext{
* Correspondence: menard.ml@pediatrie-chulenval-nice.fr

'University Department of Child and Adolescent Psychiatry, Nice Children's

Hospitals CHU-Lenval, 57 avenue de la Californie, 06200 Nice, France

Full list of author information is available at the end of the article
} 


\section{Background}

The prescription of psychotropics has increased in the pediatric population all over the world since about 15 years. This increase is widely varying depending on the country and molecules, ranging from 1.5- to 5-times in many European countries and the United States $[1,2]$. In France the frequency of annual psychotropic prescriptions in children and adolescents is about 2.2\% [2]. The increase in antipsychotic (AP) use is explained by a dramatic increase in atypical or second-generation AP (SGA) use, while typical or first-generation AP (FGA) prescriptions decreased [3]. SGA have a comparable efficiency to FGA with better neuromuscular safety [4]. Many AP medications in the pediatric population are prescribed off-label, especially in very young children $[5,6]$. Prescriptions are therefore frequently unsupported by rigorous scientific evidence. SGA drugs are actually widely used to treat many psychiatric disorders such as schizophrenia, bipolar, autistic spectrum, attention deficit hyperactivity or behavior disorders in the pediatric population [7-9]. However, the pediatric literature data show several adverse events (AE) in children and adolescents treated with AP [10-14]: muscular (muscle weakness, extrapyramidal syndrome, akathisia, dystonia, dyskinesia, catatonia), metabolic (weight gain, obesity, dyslipidemia, hyperglycemia, diabetes, insulin resistance, hypertriglyceridemia, hypercholesterolemia) and endocrine AE (hyperprolactinemia, vitamin D deficiency). Children treated with SGA are more likely than adults to experience AE. Woods et al. [15] studied more than 4 million prescriptions of olanzapine. They observed that the relative risk of sedation, weight gain, dystonia and tardive dyskinesia is 2 to 5 times greater in children or adolescents than in adults. Additionally, only few prospective studies examine antipsychotic adverse events in naive pediatric populations [16-18]. Several European and American authors are worried about long-term effects of antipsychotic medication on children's health and recommend more safety guidelines and management of adverse events [19-26]. In fact, there are currently few guidelines for the management of adverse events in youth treated by antipsychotics [27-29]. On the European level, the lack of official guidelines for standardized follow-ups in the pediatric population is surprising given the probably higher relative risk of $\mathrm{AE}$ in this population. Furthermore, the incidence of $\mathrm{AE}$ in a drug-naive population is less well documented, as the typical study populations consist of pediatric patients who have already been exposed to an antipsychotic drug [30,31]. In France, since 2007 only two second-generation antipsychotics have been granted market authorization: risperidone for severe behavioral disorders from 5 years of age; and aripiprazole for schizophrenia from the age of 15 years and recently for maniac episodes associated with bipolar I disorder from the age of 13 . The frequency of antipsychotic offlabel prescriptions is as high as 69\% in French university pediatric hospitals [32]. In March 2010, the French National Agency for Medicines and Health Products Safety (Agence nationale de sécurité du médicament et des produits de santé, ANSM) recommended cardiometabolic monitoring for all adult subjects treated with psychotropic drugs. There is no official recommendation for the safety monitoring in the pediatric population. This is paradoxical, since this population is at high risk of adverse events. In addition, adverse events during AP use in children are often poorly and insufficiently monitored in France in general practice.

\section{Clinical studies}

\section{Preliminary study}

In our own clinical experience, based on a university inpatient unit specifically aimed to treat young adolescents with a first psychotic episode, we have observed that adverse events (AE) such as weight gain, acute dystonia and catatonia were very common in these patients treated for the first time with SGA. We therefore undertook a naturalistic prospective cohort study in the University Children and Adolescent Psychiatric Department of Nice, France, in order to evaluate the incidence of AE related to SGA and we present the main results observed in our clinical population. This psychiatric department is the only inpatient adolescent psychiatric facility serving the one million and a half inhabitants of the French department of the Alpes-Maritimes. Inpatient psychotropic naive adolescents presenting a first acute psychotic episode and treated with a SGA were consecutively included in the study over a 12-month period from July 2009 to July 2010. Each patient was followed for 12 weeks.

The study was approved by Lenval Children's Hospital Scientific Committee. The following inclusion criteria were used: (1) male or female inpatient; (2) aged between 13 and 18 years; (3) requiring a SGA treatment; and (4) never before treated with any psychotropic medication. The follow-up included 4 visits: at baseline (W0), in the 48 hours before the introduction of the SGA, at 2 (W2), at 6 (W6), and at 12 weeks (W12) after the introduction of the SGA (Figure 1). The same investigator who was experienced in the use of the standardized rating scales assessed all adolescents. The clinical diagnosis was confirmed by Kiddie-SADS (2002 version), and several psychometric assessments were performed: Brief Psychiatry Rating Scale (BPRS), Positive and Negative Syndrome Scale (PANSS), Scale for the Assessment of Negative Symptoms (SANS), Young Mania Rating Scale (YMRS), Montgomery and Asberg Depression Rating Scale (MADRS) [33-37]. Neuromuscular AE were documented with the help of the Extrapyramidal Symptom Rating Scale (ESRS) and the 


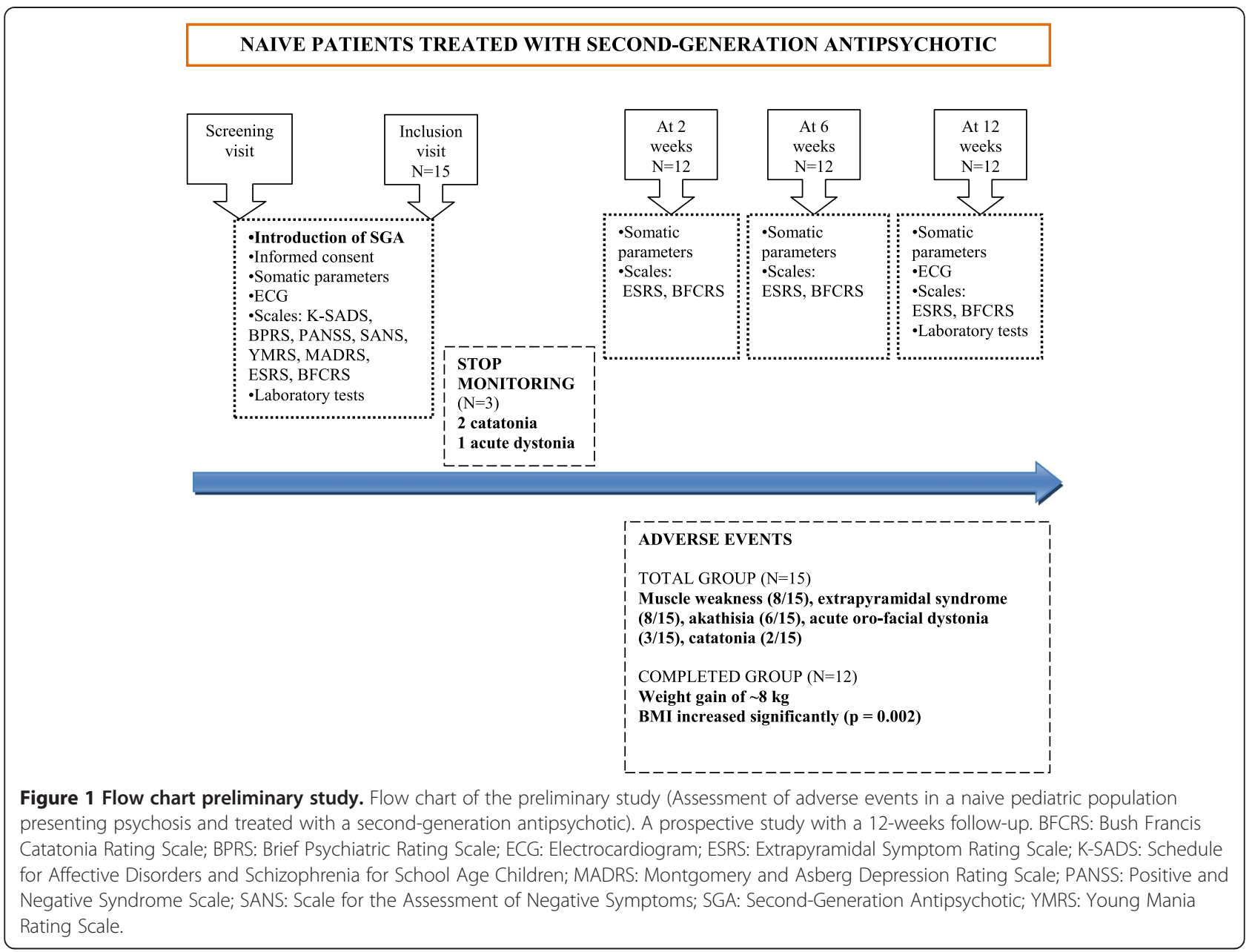

Bush Francis Catatonia Rating Scale (BFCRS) [38,39]. All laboratory assessments were performed by the same university department laboratory (complete blood count, liver enzymes, creatine phosphokinase, fasting glycemia, cholesterol (HDL, LDL, total), triglycerides, and prolactin) at baseline and at W12. Fifteen adolescents, 8 males and 7 females, were included. Their average age $( \pm \mathrm{SD})$ was $14.9 \pm 1.38$ years. Thirteen were treated with risperidone, and two with aripiprazole. The average oral dose was $2.5 \pm 1.6 \mathrm{mg} / \mathrm{d}$ for risperidone and $7.5 \pm 2.4 \mathrm{mg} / \mathrm{d}$ for aripiprazole throughout the follow-up. At baseline, DSM-IV-R diagnoses were: acute psychotic episode (15/15), schizophrenia (8/15), mood disorder (3/15), severe anxiety disorder $(2 / 15)$ and borderline personality disorder $(2 / 15)$.

We observed a high incidence of neuromuscular $\mathrm{AE}$ during the follow-up, leading to the discontinuation of AP treatment (risperidone) in 3 patients (catatonia $2 / 3$, acute oro-facial dystonia 1/3). Muscle weakness was reported in 8/15 subjects, extrapyramidal syndrome in $8 / 15$, akathisia in $6 / 15$ and acute oro-facial dystonia in $3 / 15$.
Severe catatonia symptoms were observed in 2 patients with paranoid schizophrenia at the $4^{\text {th }}$ and $7^{\text {th }}$ day of treatment while receiving a low to moderate dose of risperidone (1.5 and $2 \mathrm{mg}$ respectively). Both patients presented stupor, mutism, staring, catalepsy and rigidity. In addition, verbigeration and withdrawal with refusal to eat and drink was a clinical feature in the first patient, and echolalia and impulsivity in the second one. Patients did not have fever or dysfunctions of the autonomic nervous system. They presented high scores on the Bush Francis Catatonia Rating Scale (17 and 12 respectively). SGA was immediately stopped and patients received clonazepam at dose $0.05 \mathrm{mg} / \mathrm{kg} / \mathrm{d}$. The first patient had to be transferred to the intensive care unit for hypoglycemia and dehydration in order to receive intravenous treatment.

One patient presented acute oro-facial dystonia. AP treatment was stopped and the patient received anticholinergic medication (one dose of intramuscular tropatepine $10 \mathrm{mg}$ ).

Moderate akathisia was present in 6 patients, sometimes starting as early as 2 weeks of SGA treatment. 
Severity was evaluated using the Extrapyramidal Symptom Rating Scale (ESRS).

For all patients - with the exception for one patient who developed catatonia - creatine phosphokinase was normal during follow up despite of a significant increase ( $\mathrm{p}=0.03$, Wilcoxon test). No correlation was detected between this increase and neuromuscular AE (muscle weakness, extrapyramidal syndrome, akathisia).

The 12 patients who completed the 12 weeks followup presented a significant weight gain with $51.1 \pm$ $8.5 \mathrm{~kg}$ at W0 and $59.0 \pm 11.2 \mathrm{~kg}$ at W12 ( $\mathrm{p}=0.002$, Wilcoxon test). The BMI increased significantly from $19.0 \pm 2.5$ at W0 to $21.7 \pm 3.5$ at W12 $(\mathrm{p}=0.002)$. The observed weight gain of about $8 \mathrm{~kg}$ during 12 weeks is higher than in two other pediatric studies of comparable duration $(3,9$ et $5,3 \mathrm{~kg}$ for risperidone [40,30]; $4,4 \mathrm{~kg}$ for aripiprazole [30]; this might be explained by the small subject number or dose differences in our study.

No abnormalities were observed for the other monitored parameters, including lipid values.

In summary, we observed in our study many and serious adverse events despite the small sample size of 15 subjects. The particularity of this study is that all patients presented a first psychotic episode and had never been exposed to antipsychotic and/or other psychotropic medications before, which might partially explain this observation. For all these reasons and because of the lack of naturalistic follow-up studies of antipsychotic treatments in naive children and adolescents in
France, we wanted to continue studying at the national level.

\section{A multicenter prospective naturalistic study in antipsychotic naive children (ETAPE Study)}

In order to continue our safety monitoring project we have started a prospective, naturalistic and multicenter study to evaluate the incidence of adverse events related to the use of antipsychotic drugs in AP naive children and adolescents in France (ETAPE, Etude de la Tolérance des AntiPsychotiques chez l'Enfant) [41,42]. This study is funded by the French National Agency for Medicines and Health Products Safety (ANSM, Agence nationale de sécurité du médicament et des produits de santé) and is registered on ClinicalTrials.gov (NCT02007928) [43]. The originality of this study lies in the inclusion of a AP naive pediatric population aged 6 to 18 years in 11 French pediatric psychiatry departments. Patients are included since April 2013 and the inclusion period will be for about 2 years with a follow up of each subject of 12 months. 340 patients should be enrolled in the study. The inclusion criteria are: (1) male or female, (2) aged from 6 to 18 years, (3) treated by antipsychotic drug, (4) never having received antipsychotic treatment before or having received AP for less than 3 months which has been discontinued 6 months prior to the study. Assessments are performed at the beginning of antipsychotic treatment and at 3, 6, 9 and 12 months after the introduction of antipsychotic drug (Figure 2). Diagnosis is made by the child psychiatrist and confirmed by the Kiddie - SADS scale (Schedule for

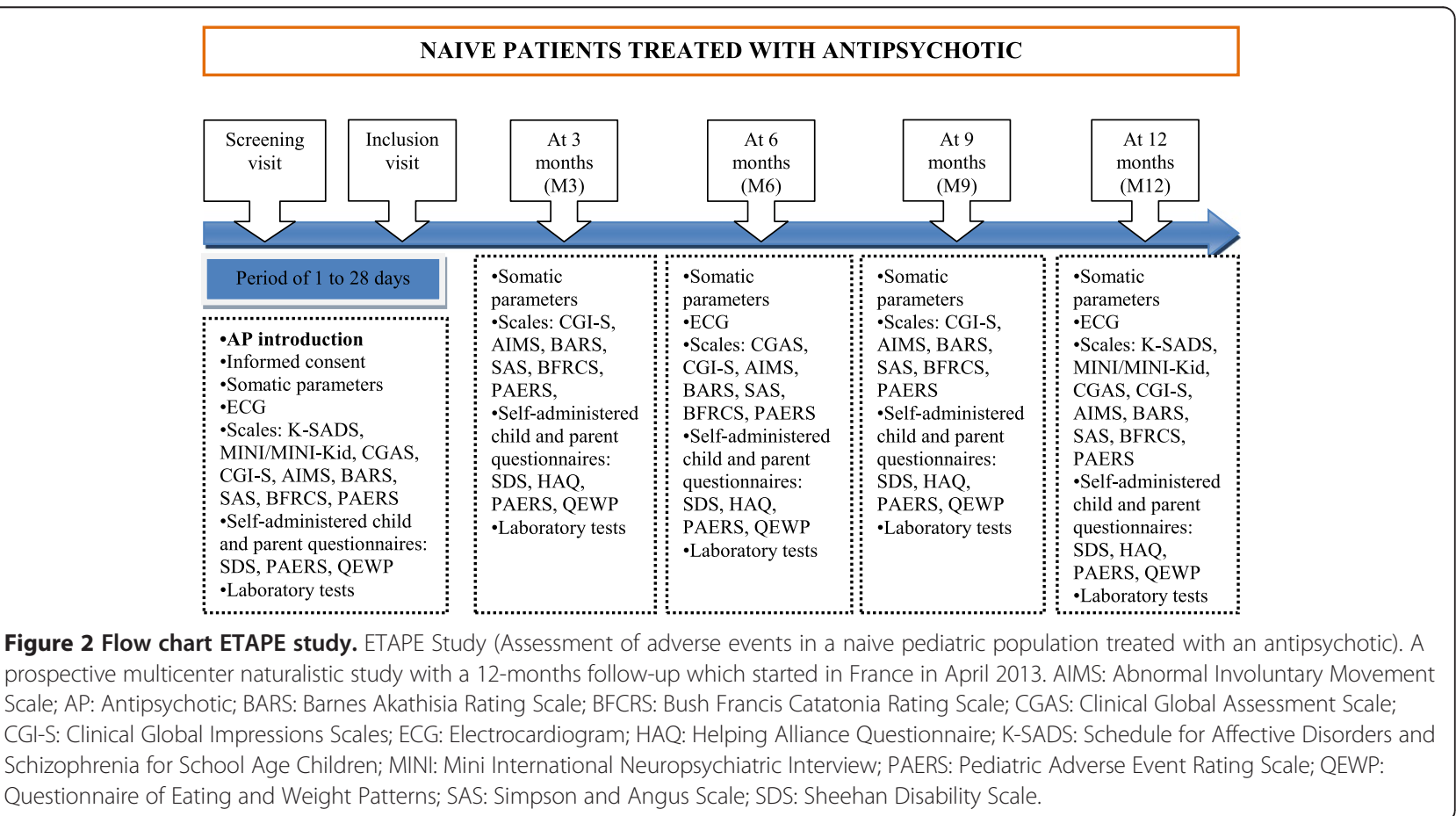


Affective Disorders and Schizophrenia for School Age Children), M.I.N.I. (The Mini International Neuropsychiatric Interview) or M.I.N.I.-Kid (depending on the age of patient) based on DSM-IV-R criteria. An exhaustive investigation of $\mathrm{AE}$ is made using the Pediatric Adverse Event Rating Scale which has been designed for the systematic identification of $\mathrm{AE}$ in the pediatric population treated with psychotropics in clinical studies by the Child and Adolescent Psychiatry Trials Network [44] and translated in French by two different experts. Neuromuscular safety is assessed by the following clinical scales: Abnormal Involuntary Movement Scale (AIMS) [45] for dyskinesia, Barnes Akathisia Rating Scale (BARS) [46] for akathisia, Simpson and Angus Scale (SAS) [47] for extrapyramidal side effects, Bush Francis Catatonia Rating Scale (BFCRS) for catatonia. Several somatic parameters are monitored (weight, height, BMI, waist circumference, blood pressure, temperature, Tanner pubertal stage). On each visit, blood samples are analyzed for complete blood count, liver enzymes, creatine phosphokinase, fasting glycemia, cholesterol (HDL, LDL, total) and triglycerides. The study also includes a follow-up of thyroid function, prolactin, insulin, HOMA, HbA1C, vitamin D and C-reactive protein. Four self-administered questionnaires are proposed to child and parent: (1) Sheehan Disability Scale (SDS) for the evaluation of functional impairment in school, social and family life [48], (2) Helping Alliance Questionnaire (HAQ) to assess the relation between the patient, his family and the therapist [49], (3) Pediatric Adverse Event Rating Scale (PAERS) for the evaluation of side effects, (4) Questionnaire of Eating and Weight Patterns (QEWP) to specify eating disorders like bulimia or binge eating [50]. An electrocardiogram with the measurement of the QT interval is performed at baseline, 6 and 12 months.

\section{Conclusion}

In the pediatric population, the use of antipsychotic drugs has been continously increasing over the last decade. In France, prescriptions are frequently off-label and starting more and more in young children. Adverse events are often not optimally monitored and without systematic follow-up. In addition, the lack of studies in children also leads to a safety concern.

The data of our preliminary study underline a high prevalence of neuromuscular AE in fifteen psychotropic drug naive inpatient adolescents treated with SGA for a first psychotic episode. We therefore started a multicenter prospective and naturalistic study to evaluate AP adverse events in naive children and adolescents in France. The results of ETAPE's study will have a major impact in terms of public mental health services in our country and must help to develop official recommendations for antipsychotic treatment and its safety monitoring in the pediatric population.

\section{Implications and contribution}

Beyond the available literature, more research is urgently needed about adverse events of antipsychotics in the pediatric population in order to develop official recommendations. However, enough is known to emphasize the necessity of thorough and systematic monitoring of $\mathrm{AE}$ in this vulnerable population. Furthermore, in the light of the growing trend to prescribe these drugs to children and adolescents, practitioners need to be aware of the necessity of optimal safety management.

\section{Informed consent}

The study was approved by Lenval Children's Hospital Scientific Committee. Written informed consent was obtained from the patients and their parents.

\section{Competing interests}

The authors have no conflicts of interest relevant to this article to disclose. Philippe Auby is a Lundbeck employee and the views presented in this article are those of the author alone, and should not be understood or quoted as being made on behalf of $\mathrm{H}$. Lundbeck A/S or any of Lundbeck's affiliate.

\section{Authors' contributions}

MLM is the principal author of the study, and guarantor for the results. FA and MLM contributed to the conceptualization of the study and data analysis. All authors contributed to the writing of the manuscript. All authors read and approved the final manuscript.

\section{Acknowledgements}

The authors would like to thank the patients and their parents for participation in these studies. The ETAPE study is supported by the French National Agency for Medicines and Health Products Safety (Agence Nationale de Sécurité du Medicament et des produits de santé, ANSM).

\section{Author details}

${ }^{1}$ University Department of Child and Adolescent Psychiatry, Nice Children's Hospitals CHU-Lenval, 57 avenue de la Californie, 06200 Nice, France.

${ }^{2}$ Paediatrics and CDC, Lundbeck SAS, 92445 Issy-les-Moulineaux, France.

Received: 22 February 2014 Accepted: 2 June 2014

Published: 13 June 2014

\section{References}

1. Wong IC, Murray ML, Camilleri-Novak D, Stephens P: Increased prescribing trends of paediatric psychotropic medications. Arch Dis Child 2004, 89:1131-1132.

2. Acquaviva E, Peyre H, Falissard B: Panorama de la prescription et de la consommation des psychotropes chez l'enfant et l'adolescent en France. Neuropsychiatr Enf Adolesc 2012, 60:77-85.

3. Patel NC, Crismon ML, Hoagwood K, Johnsrud MT, Rascati KL, Wilson JP, Jensen PS: Trends in the use of typical and atypical antipsychotics in children and adolescents. J Am Acad Child Adolesc Psychiatry 2005, 44:548-556.

4. Kumra S, Oberstar JV, Sikich L, Findling RL, McClellan JM, Vinogradov S, Schulz SC: Efficacy and tolerability of second-generation antipsychotics in children and adolescents with schizophrenia. Schizophr Bull 2008, 34:60-71.

5. Harrison JN, Cluxton-Keller F, Gross D: Antipsychotic medication prescribing trends in children and adolescents. J Pediatr Health Care 2012, 2:139-145.

6. Vitiello B, Correll C, van Zwieten-Boot B, Zuddas A, Parellada M, Arango C: Antipsychotics in children and adolescents: Increasing use, evidence for efficacy and safety concerns. Eur Neuropsychopharmocol 2009, 19:629-635.

7. Matone M, Localio R, Huang YS, dosReis S, Feudtner C, Rubin D: The relationship between mental health diagnosis and treatment with second-generation antipsychotics over time: a national study of U.S. Medicaid-enrolled children. Health Serv Res 2012, 47:1836-1860. 
8. Fraguas D, Correll CU, Merchan-Naranjo J, Rapado-Castro M, Parellada M, Moreno C, Arango C: Efficacy and safety of second-generation antipsychotics in children and adolescents with psychotic and bipolar spectrum disorders: comprehensive review of prospective head-tohead and placebo-controlled comparisons. Eur Neuropsychopharmacol 2011, 21:621-645.

9. Zuddas A, Zanni R, Usala T: Second generation antipsychotics (SGAs) for non-psychotic disorders in children and adolescents: a review of the randomized controlled studies. Eur Neuropsychopharmacol 2011, 21:600-620.

10. Bonnot $\mathrm{O}$, Holzer L: Utilisation des antipsychotiques chez l'enfant et I'adolescent. Neuropsychiatr Enf Adolesc 2012, 60:12-19.

11. Cohen D, Bonnot O, Bodeau N, Consoli A, Laurent C: Adverse effects of second-generation antipsychotics in children and adolescents: $A$ Bayesian meta-analysis. J Clin Psychopharmacol 2012, 32:309-316.

12. Bonnot O, Inaoui R, Raffin-Viard M, Bodeau N, Coussieu C, Cohen D: Children and adolescents with severe mental illness need Vitamin D supplementation regardless of disease or treatment. J Child Adolesc Psychopharmacol 2011, 21:157-161.

13. Correll CU, Kane JM, Manu P: Obesity and coronary risk in patients treated with second-generation antipsychotics. Eur Arch Psychiatry Clin Neurosci 2011, 261:417-423.

14. Goeb JL, Duhamel A, Kechida G, Bordetd R, Thomase P, Deliona P, Jardria R: Effets secondaires métaboliques de la risperidone dans les schizophrénies à début précoce. Encéphale 2010, 36:242-252.

15. Woods SW, Martin A, Spector SG, McGlashan TH: Effects of development on olanzapine associated adverse events. J Am Acad Child Adolesc Psychiatry 2002, 41:1439-1446.

16. Merchán-Naranjo J, Tapia C, Bailón C, Moreno C, Baeza I, Calvo-Escalona R, Morer A, Martínez-Cantarero C, Nestares PA, Alda JÁ, Muñoz D, Arango C: Secondary effects of antipsychotic treatment in naïve or quasi-naïve children and adolescents: design of a follow-up protocol. Rev Psiquiatr Salud Ment 2012, 5:217-228

17. San L, Arranz B, Perez V, Safont G, Corripio I, Ramirez N, Dueñas R, Alvarez E: One-year, randomized, open trial comparing olanzapine, quetiapine, risperidone and ziprasidone effectiveness in antipsychoticnaive patients with a first-episode psychosis. Psychiatry Res 2012, 200:693-701.

18. Andersen R, Fagerlund B, Rasmussen H, Ebdrup BH, Aggernaes B, Gade A, Oranje B, Glenthoj B: Cognitive effects of six months of treatment with quetiapine in antipsychotic-naïve first-episode schizophrenia. Psychiatry Res 2011, 187:49-54.

19. Raffin M, Gianitelli M, Consoli A, Bonnot O, Menard ML, Askenazy F, Laurent C, Cohen D: Management of adverse effects of secondgeneration antipsychotics in youth. Curr Treat Options Psychiatr 2014, doi:10.1007/s40501-013-0007-9.

20. Ben AL: Antipsychotics in pediatric and adolescent patients: a review of comparative safety data. J Affect Disord 2012, 138(Suppl):S22-S30.

21. De Hert M, Dobbelaere M, Sheridan EM, Cohen D, Correll CU: Metabolic and endocrine adverse effects of second-generation antipsychotics in children and adolescents: a systematic review of randomized, placebo controlled trials and guidelines for clinical practice. Eur Psychiatry 2011, 26:144-158

22. Bonnot O, Inaoui R, Lloret Linares C, Cohen D: Principes de surveillance des effets métaboliques, de l'hyperprolactinémie et du rythme cardiaque pour les antipsychotiques atypiques chez l'enfant et I'adolescent. Neuropsychiatr Enf Adolesc 2010, 58:431-438.

23. Maayan L, Correll CU: Management of antipsychotic-related weight gain. Expert Rev Neurother 2010, 10:1175-1200.

24. Morrato E, Nicol GE, Maahs D, Druss BG, Hartung DM, Valuck RJ, Campagna E, Newcommer JW: Metabolic screening in children receiving antipsychotic drug treatment. Arch Pediatr Adolesc Med 2010, 164:344-351.

25. Correll CU: Assessing and maximizing the safety and tolerability of antipsychotics used in the treatment of children and adolescents. J Clin Psychiatry 2008, 69(Suppl4):26-36.

26. Fleischhaker $C$, Heiser $P$, Hennighausen $K$, Herpertz-Dahlmann $B$, Holtkamp K, Mehler-Wex C, Rauh R, Remschmidt H, Schulz E, Warnke A: Clinical drug monitoring in child and adolescent psychiatry: side effects of atypical neuroleptics. J Child Adolesc Psychopharmacol 2006 16:308-316
27. Ho J, Pangiotopoulos C, McCrindle B, Grisaru S, Pringsheim T, and CAMESA guideline group: Management recommendations for metabolic complications associated with second generation antipsychotic use in children and youth. Paediatr Child Health 2011, 16:575-580.

28. Pringsheim T, Pangiotopoulos C, Davidson J, Ho J, and CAMESA guideline group: Evidence-based recommendations for monitoring safety of second generation antipsychotics in children and youth. J Can Acad Child Adolesc Psychiatry 2011, 20:218-233.

29. Pringsheim T, Doja A, Belanger S, Patten S, CAMESA guideline group: Treatment recommendations for extrapyramidal side effects associated with the second-generation antipsychotic use in child and youth. Paediatr Child Health 2011, 16:590-598.

30. Correll CU, Manu P, Olshanskiy V, Napolitano B, Kane JM, Malhotra AK: Cardiometabolic risk of second-generation antipsychotic medications during first-time use in children and adolescents. JAMA 2009, 302:1765-1773.

31. Perez-Iglesias R, Mata I, Pelayo-Teran JM, Amado JA, Garcia-Unzueta MT, Berja A, Martinez-Garcia O, Vazquez-Barquero JL, Crespo-Facorro B: Glucose and lipid disturbances after 1 year of antipsychotic treatment in a drug-naïve population. Schizophr Res 2009, 107:115-121.

32. Winterfeld U, le Heuzey MF, Acquaviva E, Mouren MC, Brion F, Bourdon O: Utilisation hors autorisation de mise sur le marché (AMM) des psychotropes en pédiatrie : une étude prospective. Arch Pediatr 2009, 16:1252-1260

33. Pichot P, Overall JE, Samuel-Lajeunesse B, Drefus JF: Structure factorielle de l'échelle abrégée d'appréciation psychiatrique. Rev Psychol Appl 1969, 19:218-232.

34. Kay SR, Opler LA, Fiszbein A: Manuel de cotation de la PANSS (1986), traduction française Lépine JP. 1988.

35. Lecrubier $Y$, Boyer P: Fiche descriptive et traduction française de la SANS. Psychiatr Psychobiol 1987, 2:414-423.

36. Favre S, Aubry JM, Gex Fabry M, Ragama Pardos E, McQuillan A, Bertschy G: Traduction et validation française de l'échelle de manie de Young (YMRS). Encéphale 2003, 29:499-505.

37. Lemperière $T$, Lépine JP, Rouillon F, Hardy P, Ades J, Luaute JP, Ferrand I: Comparaison de différents instruments d'évaluation de la dépression à l'occasion d'une étude sur l'Athymil $30 \mathrm{mg}$. Ann Med Psychol 1984, 1984(142):1206-1212.

38. Chouinard G, Margolese HC: Manual for the Extrapyramidal Symptom Rating Scale (ESRS). Schizophr Res 2005, 76:247-265.

39. Bush G, Fink M, Petrides G, Dowling F, Francis A: Catatonia I: rating scale and standardized examination. Acta Psychiatr Scand 1996, 93:129-136.

40. Ratzoni G, Gothelf D, Brand-Gothelf A, Reidman J, Kikinzon L, Gal G, Phillip M, Apter A, Weizman R: Weight gain associated with olanzapine and Risperidone in adolescent patients: a comparative prospective study. J Am Acad Child Adolesc Psychiatry 2002, 41:337-343.

41. Menard ML, Askénazy F: Evaluation de l'incidence des événements indésirables sous antipsychotique en population pédiatrique naïve (Etude ETAPE : Etude de la Tolérance des AntiPsychotiques chez I'Enfant). Neuropsychiatr Enf Adolesc 2013, 2013(61):131-132.

42. Menard ML, Askénazy F, Auby P, Bonnot O, Cohen D: Sécuriser la prescription des antipsychotiques en population pédiatrique : une étude multicentrique française en population naïve. Encéphale 2013, 39:313-314.

43. Assessment of adverse events in a naive pediatric population treated with an antipsychotic. [http://clinicaltrials.gov/show/NCT02007928]

44. March JS, Silva SG, Compton S, Anthony G, DeVeaugh-Geiss J, Califf R, Krishnan R: The Child and Adolescent Psychiatry Trials Network (CAPTN). J Am Acad Child Adolesc Psychiatry 2004, 43:515-518.

45. Guy W: ECDEU Assessment Manual for Psychopharmacology: Revised (DHEW publication number ADM 76-338). Rockville, MD: US Department of Health, Education and Welfare, Public Health Service, Alcohol, Drug Abuse and Mental Health Administration, NIMH Psychopharmacology Research Branch, Division of Extramural Research Programs; 1976:534-537.

46. Barnes TR: A rating scale for drug-induced Akathisia. Br J Psychiatry 1989, 154:672-676.

47. Simpson GM, Angus JW: A rating scale for extra-pyramidal side effects. Acta Psychiatr Scand 1970, 212:11-19.

48. Whiteside SP: Adapting the Sheehan disability scale to assess child and parent impairment related to childhood anxiety disorders. J Clin Child Adolesc Psychol 2009, 38:721-730. 
49. Kermarrec S, Kabuth B, Bursztejn C, Guillemin F: French adaptation and validation of the helping alliance questionnaires for child, parents and therapist. Can J Psychiatry 2003, 51:913-922.

50. Johnson WG, Grieve FG, Adams CD, Sandy J: Measuring binge eating in adolescents: adolescent and parent versions of the questionnaire of eating and weight patterns. Int J Eat Disord 1999, 26:301-314.

doi:10.1186/1753-2000-8-18

Cite this article as: Menard et al:: Preliminary and ongoing French multicenter prospective naturalistic study of adverse events of antipsychotic treatment in naive children and adolescents. Child and Adolescent Psychiatry and Mental Health 2014 8:18.

\section{Submit your next manuscript to BioMed Central and take full advantage of:}

- Convenient online submission

- Thorough peer review

- No space constraints or color figure charges

- Immediate publication on acceptance

- Inclusion in PubMed, CAS, Scopus and Google Scholar

- Research which is freely available for redistribution 